\title{
AC 2007-3093: CREATIVE PROBLEM SOLVING IN CAPSTONE DESIGN
}

\section{Edward Lumsdaine, Michigan Technological University}

Dr. Edward Lumsdaine is currently Professor of Mechanical Engineering at Michigan Technological University and Special Professor of Business, Institute for Enterprise and Innovation, University of Nottingham (England). For many years he was management consultant at Ford Motor Company and in the last few years helped to develop and direct a high-tech education and training program in the use of design and data management tools. In 1994 he received the ASEE Chester F. Carlson award for innovation in engineering education. He has co-authored several books and teaches classes and workshops in creative problem solving, engineering design, entrepreneurship and innovation - a synthesis of many years of experience working as engineer in industry as well as serving as dean of engineering and professor at six different universities in the U.S. and four different universities abroad. His engineering specialties are in aero-acoustics, vibration, heat transfer, fluid mechanics, solar energy, and engineering design. He has published over 100 papers in these fields. Dr. Lumsdaine is a Fellow of ASME (American Society of Mechanical Engineering) and RSA (the Royal Society of Arts) in the UK. Contact information: lumsdain@mtu.edu and www.InnovationToday.biz. 


\title{
Creative Problem Solving in Capstone Design
}

\begin{abstract}
This paper describes the 2006/07 capstone design course at Michigan Technological University, which had 121 students assigned to 24 project teams. The teams were formed based on the Herrmann Brain Dominance Instrument (HBDI) results, sponsor requirements, student GPA and special qualifications. During the first semester, the emphasis of the course was on creative problem solving, team building, and learning the 12-step design process with the associated documentation and thinking skills. During the second semester, the emphasis shifted to design for X. Other topics covered were prototyping, optimization and quality (Six Sigma, FMEA, QFD, and robust engineering) as well as new data management tools and ethics.
\end{abstract}

First semester results showed marked improvement in written and oral communication and understanding of team development and dealing with conflict or language barriers. None of the teams were found to be dysfunctional - this achievement was particularly noted by Mechanical Engineering staff involved with the design teams. Also, all project sponsors were satisfied with the progress of their teams. One team expressed the value of the new approach this way: "We would have charged ahead with our first idea, but then we were "forced" to use the creative problem solving process. We now see that our final design solution is far superior to what we would have accomplished with our initial concept and limited range of thinking modes."

\section{Background and Opportunity}

Creative problem solving was a required freshman course in Electrical Engineering at Michigan Technological University from 1994 to 1998 . Also, a creative problem solving course ${ }^{1}$ was taught for general engineering; it was open as a technical elective to all other students. However, after 2000, when the university switched from a quarter to a semester system, a common first year was instituted for all engineering students, and creative problem solving was no longer included in the curriculum, except as a one-credit module in the Engineering Enterprise Program.

The two-semester capstone design course in the Mechanical Engineering-Engineering Mechanics Department was taught for many years by different professors. From all these years, little documentation exists in terms of successes and challenges. The professors mostly taught the course according to their individual perceptions and their preferred textbooks apart from industrial design experience. A design committee manages the course logistics, provides oversight of the projects, and acts as liaison for the interdisciplinary projects involving other engineering departments and the School of Business. The Committee influences the direction of the course. However, the members were caught in a campus culture that for years has been riskaverse and lacks a global vision for engineering education. When one of the design professors retired and the other (a key member of the design committee) went on sabbatical, an opportunity opened to fully implement a capstone design sequence that had previously been co-taught on an experimental basis ${ }^{2}$. Previous course outcomes were very uneven, ranging from award-winning teams to dysfunctional teams producing hurried, mediocre, and superficial project results. 


\section{Course Goals and Objectives}

One of the goals of the course was meeting the ABET 2000 criteria (listed as the first eleven criteria of Table 1). A broader, long-term objective-beyond these "minimum" criteria-was to prepare students to be able to compete successfully in the global marketplace. Two additional objectives existed that at times appeared to be in conflict: satisfying the project sponsors (who are paying up to $\$ 15,000$ per team), and a thorough teaching of the conceptual design process (often overlooked but equally important). Many students and faculty assume that students will learn the process and associated thinking paradigms simply by doing a design project. However, two ways of acquiring knowledge are involved and necessary for optimal learning ${ }^{3,4}$ : explicit knowledge (with the underlying thinking skills made transparent) and tacit learning, where the skills are applied and experienced, yet are often non-verbalized.

Table 1 Key Course Components that Address the Objectives and Criteria

\begin{tabular}{|c|c|c|c|c|c|c|c|c|c|c|}
\hline \multirow{3}{*}{$\begin{array}{c}\text { Why } \\
\text { Objectives }\end{array}$} & \multirow{3}{*}{$\begin{array}{c}\text { What } \\
\text { Criteria }\end{array}$} & \multicolumn{4}{|c|}{ Features } & \multicolumn{5}{|c|}{ Logistics } \\
\hline & & \multirow{2}{*}{ 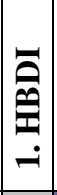 } & \multirow{2}{*}{$\begin{array}{l} \\
\tilde{2} \\
\tilde{u} \\
\dot{\sim}\end{array}$} & \multirow{2}{*}{ 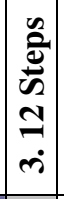 } & \multirow{2}{*}{ 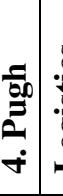 } & \multirow{2}{*}{\multicolumn{2}{|c|}{ 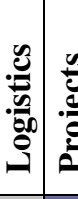 }} & \multirow{2}{*}{ ט.: } & \multirow{2}{*}{$=\frac{n}{2}$} & \multirow{2}{*}{ 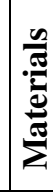 } \\
\hline & & & & & & & & & & \\
\hline \multirow{4}{*}{$\begin{array}{c}\text { Meet ABET } \\
\text { Criteria }\end{array}$} & 1. Development of student creativity & & & & & & & & & \\
\hline & 2. Use of open-ended problems & & & & & & & & & \\
\hline & 3. Alternate design solutions and decision rationale & & & & & & & & & \\
\hline & 4. Use of modern design theory and methodologies & & & & & & & & & \\
\hline \multirow{4}{*}{$\begin{array}{l}\text { Succeed in a } \\
\text { Globally } \\
\text { Competitive } \\
\text { World }\end{array}$} & 5. Formulation of design statements and specifications & & & & & & & & & \\
\hline & 6. Feasibility considerations & & & & & & & & & \\
\hline & 7. Consideration of production processes & & & & & & & & & \\
\hline & 8. Concurrent engineering design & & & & & & & & & \\
\hline \multirow{3}{*}{$\begin{array}{l}\text { Learn the } \\
\text { Conceptual } \\
\text { Design } \\
\text { Process }\end{array}$} & 9. Detailed system description & & & & & & & & & \\
\hline & 10. Use of teams in problem solving and design work & & & & & & & & & \\
\hline & 11. Realistic constraints (DFX, economic factors, etc.) & & & & & & & & & \\
\hline \multirow{5}{*}{$\begin{array}{l}\text { Meet Project } \\
\text { Sponsor } \\
\text { Requirements }\end{array}$} & 12. Development of related communication skills & & & & & & & & & \\
\hline & 13. Production of required documentation & & & & & & & & & \\
\hline & 14. Ability to do whole-brain thinking & & & & & & & & & \\
\hline & 15. Ability to apply the creative problem solving process & & & & & & & & & \\
\hline & 16. Achieve an excellent project outcome & & & & & & & & & \\
\hline
\end{tabular}

By integrating the creative problem solving process into conceptual design, a dynamic is created for efficient learning which involves both explicit and tacit components in the most effective sequence 5 . The goal is to provide a structure that will encourage students to follow the optimal sequence of steps to set the stage for a superior project outcome coupled with a solid understanding of the conceptual design process. Therefore, the last five criteria of Table 1 relate to capabilities that will enable students to meet sponsor expectations. They will also help students to create change and understand innovation in the context of the global marketplace. 
The four special features of the course listed in Table 1 will be discussed first: (1) the Herrmann Brain Dominance Instrument (HBDI) as a basis for forming balanced project teams; (2) the creative problem solving process; (3) the 12 steps to quality by design, and (4) the Pugh method for developing "best" concepts. Next, the logistics of the course will be presented (including syllabus, projects, grading, advising, and required materials), followed by a discussion of results and recommendations.

\section{Feature 1: The Herrmann Brain Dominance Instrument (HBDI)}

The Herrmann Brain Dominance Instrument (HBDI) was used by the instructor to form mentally balanced project teams. In such teams, the students learn to communicate and work with people who have different thinking preferences ${ }^{6,7,8}$ — which in turn should lead to optimal project results. Although it is expensive, there is simply no better tool for this purpose, as concluded by the extensive Coffield report ${ }^{9}$ which compares thirteen models of learning styles used in the UK. The four distinct ways of thinking and "knowing" of the Herrmann model are shown in Figure 1.

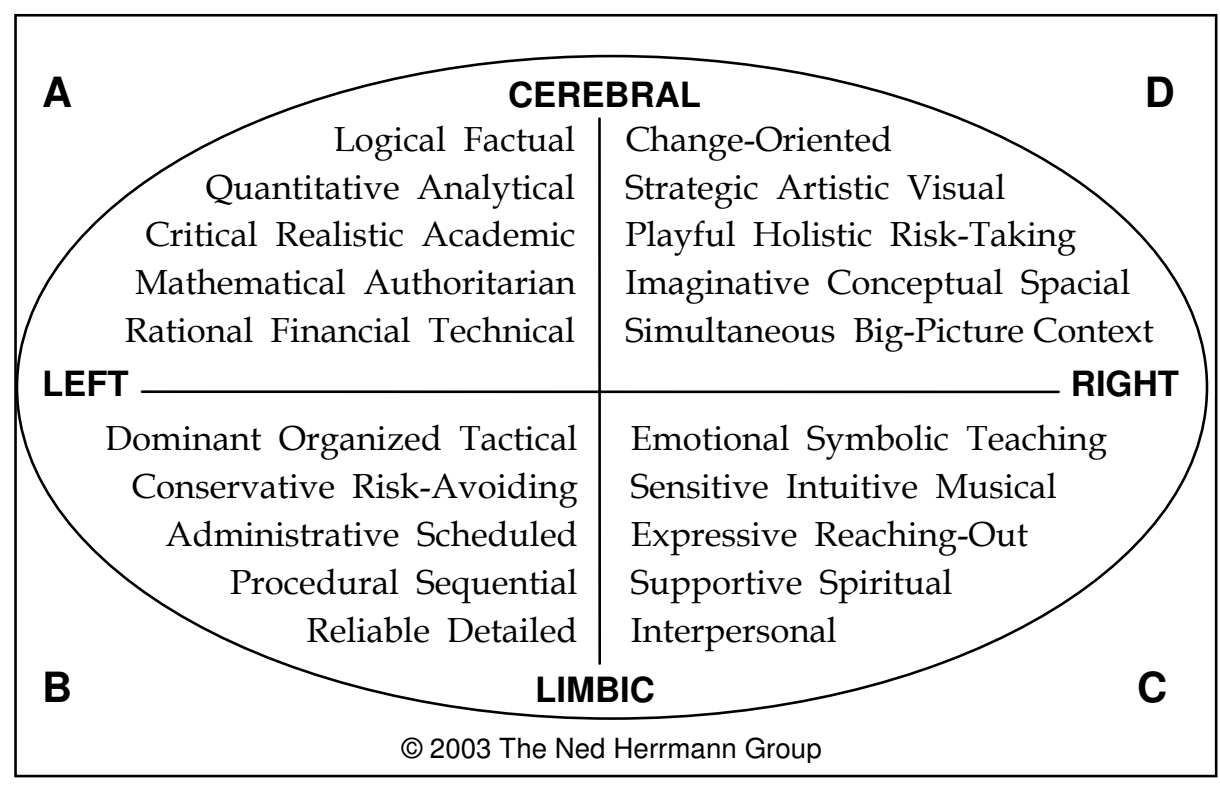

Figure 1

Thinking characteristics and behavioral clues of the four-quadrant Herrmann model of brain dominance

Each person is a unique mix of these thinking preferences and has one or more strong dominances. Dominance has advantages: quick response time and higher skill level. People use the dominant mode for learning and problem solving:

- Quadrant A thinkers typically analyze a situation carefully before making a rational decision based on the available data and the bottom line.

- Quadrant B thinkers will follow a very detailed, cautious, step-by-step procedure.

- Quadrant C thinkers prefer to talk the problem over with a team and will solve the problem intuitively.

- Quadrant D thinkers will see the situation in a broader context and will look for alternatives.

Because it takes more mental energy to use less preferred thinking modes, using these modes is exhausting and may even be uncomfortable and is thus avoided. Also, people with diagonally opposite modes (refer to Figure 1) have great difficulty communicating and understanding each 
other because they see the world through very different filters. Is there a best way? Ned Herrmann found that each brain mode is best for the tasks it was designed to perform. People can learn to use all modes comfortably for whole-brain thinking and problem solving. In the capstone design course, this process is integrated into the 12 steps of conceptual design.

Students in the 2006-2007 capstone course completed the HBDI survey form online about two weeks prior to the start of the course. The overall HBDI profile "tilt" (preference map) of the class is shown in Figure 2. Longitudinal research ${ }^{7}$ discovered that most right-brain dominant students either drop out of engineering or become more left-brain as they proceed through the strongly analytical curriculum. Judging from HBDI data over several years, the ABET 2000 criteria seem to have had little if any impact so far in increasing the average HBDI scores in quadrants $\mathrm{C}$ and D for the capstone students at MTU.

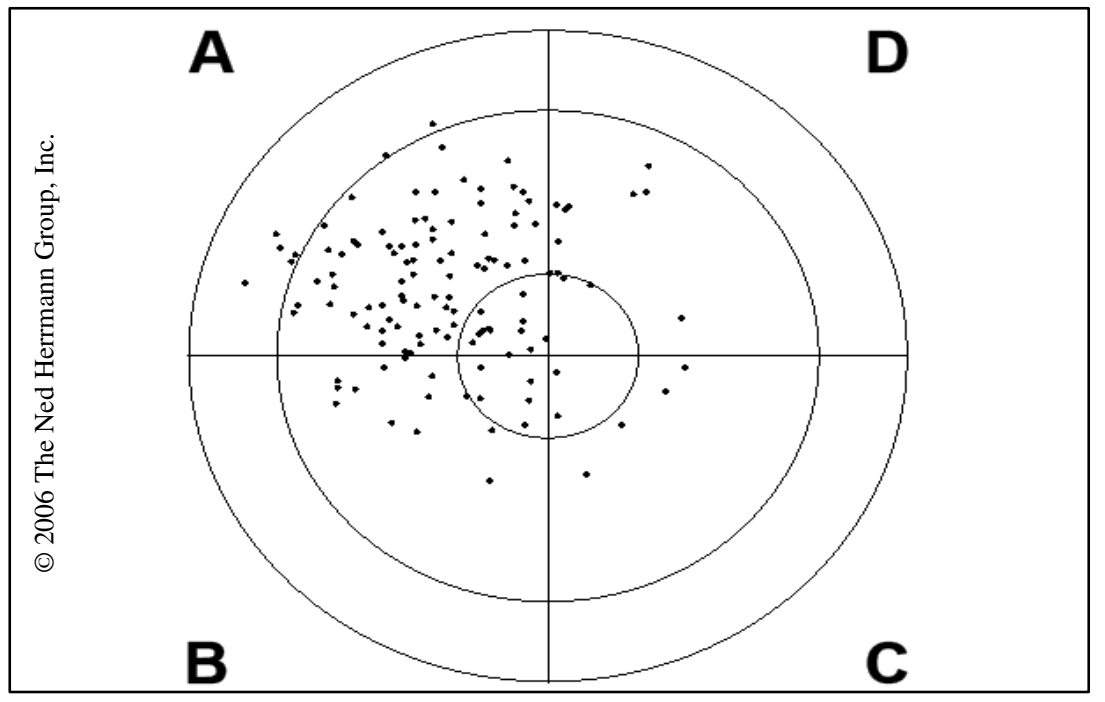

Figure 2

Thinking preference map for capstone design $(N=118)$.

The average HBDI profile score for the quadrants were $A=92, B=77, C=49$, and $D=70$. A score $>66$ indicates a strong preference, a score between 34-66 comfort in usage, and a score $<34$ a tendency to avoidance.

\section{Preparations for forming balanced teams:}

1. After students completed the on-line HBDI survey form, the results were presorted into five homogeneous groupings and color-coded. The groups for the 2006/07 capstone design class were: $\mathrm{AD}=$ yellow, very strong $\mathrm{A}=$ blue, $\mathrm{A}=$ purple, $\mathrm{BA}=$ green, multi-dominant = brown.

2. Because very few engineering students are $\mathrm{C}$-dominant, the $20 \%$ with the highest $\mathrm{C}$ scores were identified, even though they had stronger dominances in other quadrants. They were color-coded according to their strongest preferences and were marked with an orange dot.

3. Also, the $20 \%$ with the lowest $\mathrm{C}$ scores were identified; these usually tend to avoid this type of thinking and would rather work alone. A team with more than one of these has a good chance of being dysfunctional. These were also color-coded according to their strongest preferences and were further identified with a penciled circle.

4. A roster was prepared for each team, with each line identified by one of the five colors. Only one student could be entered per line to assure the team would be mentally balanced.

5. Students were asked to list their top 5 project choices; these were then tabulated by project.

\section{Steps for completing the rosters for team and project assignment:}

1. Students with special capabilities were assigned to projects to meet specified project needs and sponsor requirements. 
2. Some projects were very popular; others had only a few "applicants." Students were assigned to projects by starting with projects having the fewest interested students.

3. A student with high $\mathrm{C}$ was entered on the project roster on the identified color line, together with an orange dot marking.

4. Next, a student with low $\mathrm{C}$ was entered on the roster on the identified color line, with the penciled circle marking.

5. Then the roster was completed for the remaining colors. The purple A's were selected last. If more than one student was available, the goal was to balance the GPA of the team.

6. Finally, the average HBDI profile of the team was checked. If it deviated markedly from the class average, students with the same color code and project preferences were switched. Most teams had five members, a few required six, and a few had four (mostly due to dropouts). By the end of the second week of class, a few adjustments to teams were made to solve some unexpected problems, while still trying to maintain a balanced HBDI profile.

Figure 3a shows the composite of HBDI profiles of a team where the four students were selected by the sponsor, with an average of $A=82, B=69, C=52, D=80$. This team had one student with a strong preference in quadrant $\mathrm{C}$. In comparison, Figure $3 \mathrm{~b}$ shows a typical "engineering" project team with an average of $A=96, B=76, C=49, D=67$ (which is close to the class HBDI profile). These composite charts clearly illustrate the large diversity in thinking styles for these balanced teams (except for a common trait of low $\mathrm{C}$ in Figure $3 \mathrm{~b}$ ) - and both the explicit information about the HBDI and the tacit experience of working in the diverse teams helps the students to develop an ability to communicate with people in all quadrants.

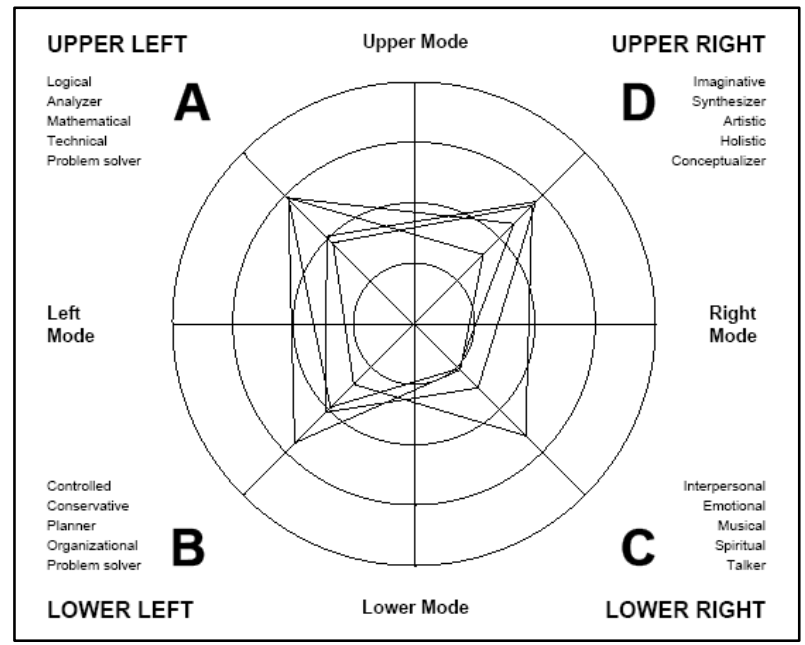

(c) The Ned Herrmann Group, Inc.

Figure 3a

HBDI group composite of a multi-disciplinary team formed specifically to meet the needs of the project sponsor.

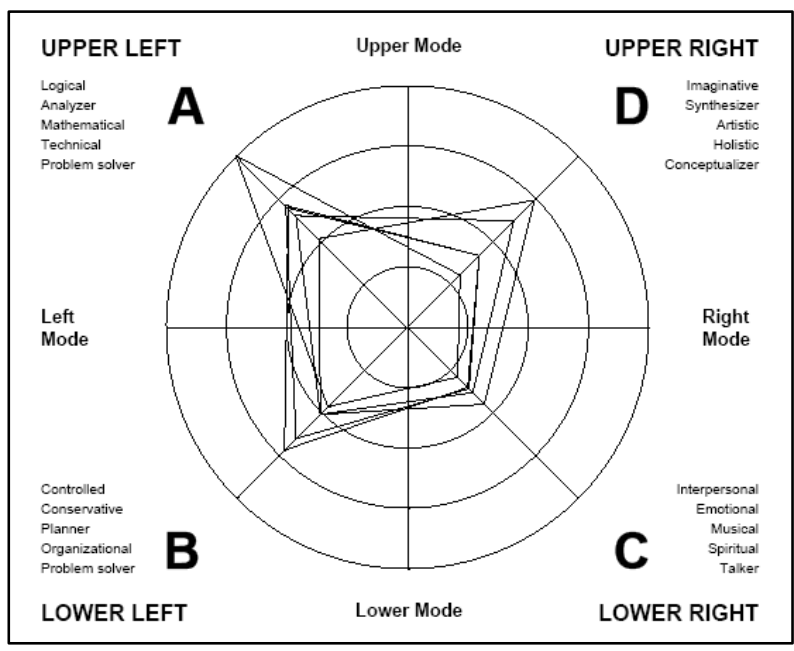

(C) The Ned Herrmann Group, Inc.

Figure $3 b$

HBDI group composite of a typical capstone design team with five mechanical engineering students.

Together with the HBDI packets, students received information on the team development process ${ }^{10}$ and the implications on communication. Their progress through the forming, storming and norming stages was monitored, and most teams (at the beginning of the second term) were well on their way to be able to reach the performing stage. The teams were enabled to deal with 
conflict (which mostly arose from differences in thinking preference). Scheduling conflicts were a common problem, but most teams found a creative way to deal with those. Lack of motivation proved to be most difficult. If a student chose not to change, the consequences were a penalty in points distributed according to the contributions each member made to the team project.

\section{Feature 2: The Steps and "Thinking" Mindsets of the Creative Problem Solving Process}

Figure 4 shows the iterative creative problem solving model and its six associated mindsets superimposed on the Herrmann model. Each mindset involves the thinking modes of two quadrants. The inner circle covers mainly the first six steps of the 12-step design process, the next six steps cycle through the outer circle several times during the process of design optimization. The figure clearly shows the whole-brain nature of the creative problem-solving process. Students are given some practice in lateral thinking and are monitored to make sure they do not skip the steps that require the "explorer" and "artist" mindsets. The mindsets are powerful metaphors and reminders of the thinking modes to be used at each design step-they go far in preventing premature convergent thinking and judgment of ideas before they had a chance to be worked into innovative concepts.

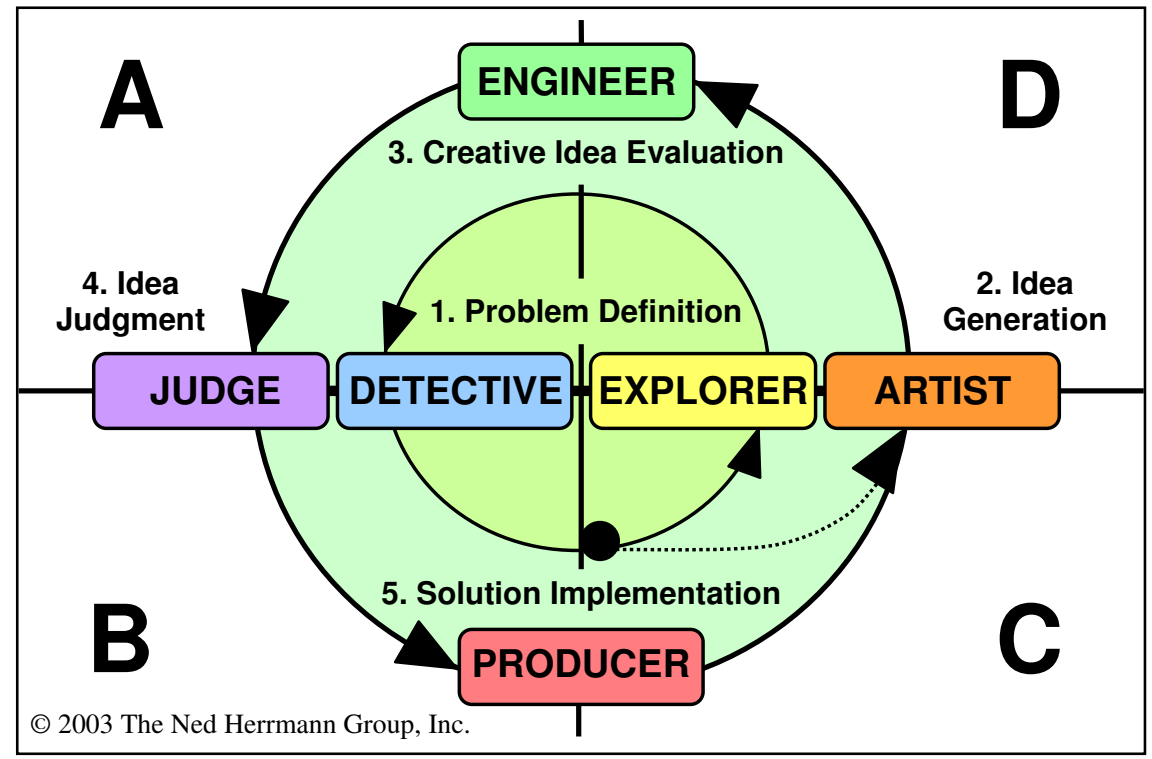

Figure 4

The creative problem solving process with its associated mindsets is shown superimposed on the Herrmann model of thinking preferences 5 .

\section{Feature 3: The 12 Steps to Quality by Design}

Engineering design in this course was defined as the communication of a set of rational decisions obtained with creative problem solving for accomplishing certain stated objectives within prescribed constraints. The design process is carried out as a structured approach, where creative problem solving is integrated at each step. This is the heart of the first semester's content and focuses heavily on the underlying thinking modes and good communication.

The twelve steps and associated documents are shown in Table 2. During the first lecture, the students received four detailed charts that showed how information flows from each step and document into the next activities, until it culminates in the completed design. These four charts are given in the Appendix. Figure A-1 shows the information flow for the problem definition 
phase (the first six design steps), Figures A-2, A-3 and A-4 the information flow for the remaining design stages. Students received just-in-time instructions and reading assignments for each step. They were required to use the formats given in the textbook for communicating the project information in tables, documents, reports, drawings, and oral presentations.

Due to time constraints, the oral design proposal presentation was limited to 3 minutes for each team, with each member having to participate. Logistically, this was done by extending the class hour by 60 minutes. The written project proposal was sent to the sponsors for comments. A number of teams had to rework their proposal - they discovered they had misunderstood what the sponsor really wanted. The oral progress report presentation was also limited to 3 minutes. These brief presentations gave an overview to the instructor of where the class as a whole was going. It also gave the students practice in speaking and held the teams accountable for keeping on track in their projects - and it let them see what the other teams were accomplishing.

Table 2 The 12 Steps of Design with Associated Documentation

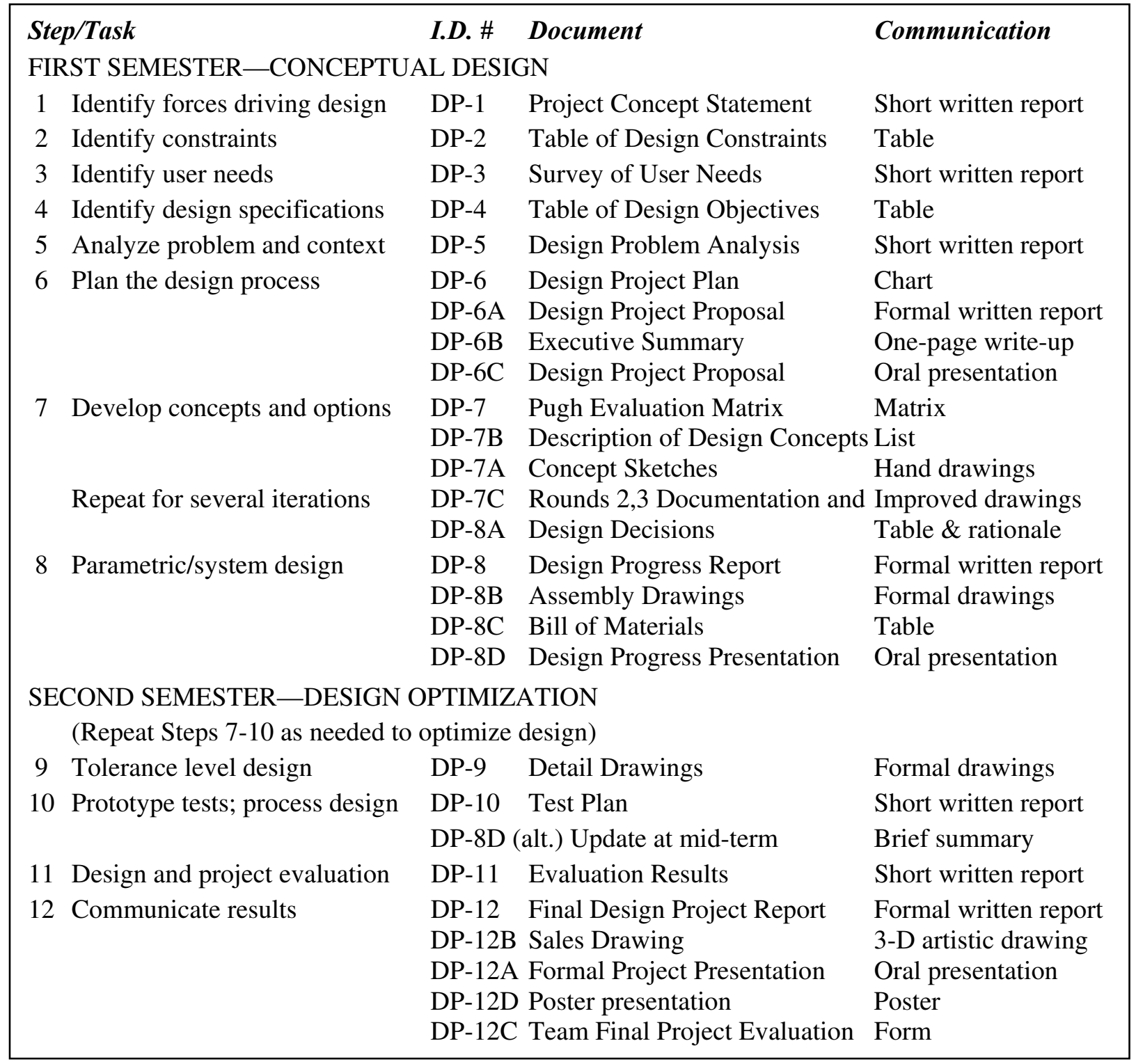


The progress reports (DP-8) were submitted shortly after mid-term. The instructor and advisors were surprised by the generally low quality and careless execution of these reports. They thus carefully read and edited these reports before returning them to the students. The general excuse given by the students was that they did not realize they were to follow the style and formats given in the textbook and in the instructions provided in the PowerPoint lectures! The decision was made not to submit these reports to the sponsors. Because a comprehensive report (DP-12 alt.) was due by the end of the first semester, the students were asked instead to correct and update their DP-8 reports and make sure that this end-of-term report did not have any of the common grammar and writing mistakes, or their grade would be lowered. The progress reports (DP-8) also showed that one team had rushed through the problem definition stage without following all the steps. The team was given a choice: to go back and do it right, or to continue with a mediocre product (and get graded accordingly).

The end-of-first-term oral presentations were 20 minutes each. Faculty members and Mechanical Engineering staff attending the presentations and commented on the good quality of the presentations and the solution concepts that had been developed in the projects. The posters were also found to be well done, even though there had been a delay in giving the students specific instructions. The written reports (DP-12 alt.) were then forwarded to the sponsors.

\section{Feature 4: The Pugh method for developing "best" concepts}

The iterative Pugh method was an important tool for evaluating creative design concepts and then developing these into synthesized, optimized and more comprehensive design solutions in design Step 7 (see Figure A-2 in the Appendix). The students were urged to use three rounds if possible_and if this made sense in their projects. Some teams applied the method to serially make decisions in the design of subsystems and parts. Some students found it difficult to use the Pugh method iteratively. Once a decision was made and the rationale was documented, they wanted to charge off in a linear direction without thinking about the potential for optimization, even though more information about different options became available. The concept of eliminating all of the "negatives" (or flaws) especially seemed to be foreign to them-instead, they relied on some weighting scheme they had devised for decision making, without explaining why the flaws were acceptable. It also appears that some sponsors encouraged students to use weighting schemes in the table of design objectives. The students then found it difficult to convert these into criteria in the Pugh method independent of the weights. If all flaws are eliminated, having the complication of weights during the conceptual design stage is not necessary for achieving a quality product — the initial weights are to be used mainly to give direction to the problem-solving process. Weights are more appropriately used later, when design decisions must be made within time constraints that do not allow additional rounds in the Pugh evaluation process, and of course with the quality tools such as QFD or Six Sigma.

The students were required to have at least three very different alternatives to bring to the Pugh evaluation. Students (and novice designers) often have a concept in mind from the beginning of the project, and they do not want to take the time to create and consider other ideas. Then too late into the project they may discover another concept that would have been better, simpler, easier to manufacture, or less costly than the one they are stuck with. To avoid such a scenario, effective designers follow a disciplined procedure for creating and evaluating design alternatives, and this 
was one of the key objectives of the course. Tools such as the Pugh method facilitate comparison and synthesis of creative ideas and alternatives early in the design process.

The students were shown a detailed Pugh method example ${ }^{11}$ in PowerPoint. The tables of design concepts and the evaluation matrixes documented the process over three rounds. Then the students were given another two-round example ${ }^{11}$ to critique as a homework assignment. Some questions about this example were included in the mid-term exam-which enabled the instructor to review and reinforce key principles and correct steps the students had misunderstood about this iterative process of finding a "best" solution.

\section{Course Logistics 1-Syllabus}

To give the students a head-start with their projects, they were given their team and project assignments at the end of the first class. At this time, they also received an introduction to the course logistics and the four information flow charts (shown in the Appendix). In the next class the HBDI results and the implications for communication and teamwork were discussed. The second week covered the identification of sponsor/customer needs and the design constraints, as well as the requirements for the design journal, followed by an overview of the creative problem solving process and associated mindsets.

By the end of the fourth week, students gave the oral team presentation of the project proposal (DP-6C in Figure A-1). To prepare them for generating creative design concepts, they had exercises in lateral thinking and a lecture on how to overcome mental blocks to creative thinking as well as an introduction to patent searching. A project planning template is provided on a CD (included with the course textbook). The first oral progress report was scheduled for the end of the seventh week (see DP-8D in Figure A-3). The lecture topics in the following weeks covered economic decision making and introduced QFD, prototyping, product liability, innovation in the workplace, and design for X. A written exam on the reading assignments was given at the beginning of Week 11. During the second semester, additional lectures on design for X, quality (including QFD, FMEA, Six Sigma, and robust engineering), data management, and ethics were given, with students refining and optimizing their design through further iterations as necessary, depending on the results of finite element analysis, prototype testing, and other investigations.

Many students lacked an understanding of quality (not only as expressed in such tools as TQM, QFD, or Six Sigma, but also in producing quality work beyond meeting minimum requirements). The student teams had occasional homework assignments to encourage them to think about various aspects of their projects, such as compiling a graphic of different stakeholders involved, developing good team ground rules, or analyzing the Pugh method example. Some students were disappointed in not receiving points for homework - these students did not heed the often repeated admonition that these tasks were for gaining knowledge rather than earning points.

\section{Course Logistics 2-Projects}

All student teams had industrial sponsors or grant support through a faculty member (NSF and/or NCIIA). Because the projects were open-ended and very different, some of the teams had difficulties meeting the design milestones (either because their sponsors were slow in providing data for the teams to proceed or because the sponsor changed the project requirements). The 
projects varied from solving engineering problems requiring extensive analysis to the development of an advanced product or redesign of a subassembly of a product or of a material handling system to the design of test stands or conversion of a waste product stream to energy.

Three interdisciplinary teams are working on developing a product that can be used to start up a business (with a business student leading the team in the writing of a business plan). The students in projects that involved product development (with the potential of starting up a business) were encouraged to take a once a week seminar course on entrepreneurship.

One company sent two staff members to Michigan Tech to work with a student team, and this company's goal is to have their student team work with the staff members to help the company not only to diversify its product lines but to actually develop a process for continuous innovation. This team was terrified at the beginning because they couldn't follow the prescribed format for design. But as they learned the creative problem solving process, they had a tool that enabled them to generate many potential product ideas and to reconcile the sponsor and class requirements. This team's HBDI composite is shown in Figure 3a.

Also, some projects were funded for three semesters or for double teams; thus these teams were required to cooperate with another team to plan the work. Some companies sponsored teams to get an advance look at students for future hires. For students without previous experience in a technical summer job, taking a plant trip and communicating with their sponsor's engineers was especially valuable.

\section{Course Logistics 3-Grading and Advising}

The instructor, team advisors, student peers, and the sponsors gave feedback and were involved in evaluating the work. Eight advisors worked with the 24 teams. By the end of Step 6, only 10\% of the total possible points could be earned. At this stage, students received much feedback and editorial help on their writing and on using proper formats for the documentation. Individual points were earned through the midterm exam, the design journal, and the allocation of points depending on their contribution to the project (as judged by the team members). The advisors (jointly with the instructor) graded the journals, the progress report and the end-of-term report. The project posters were graded jointly by the advisors and student teams. The students' peers were also involved in grading the final oral team presentations.

Grading the written reports for 24 teams by the instructor took approximately 30 hours, both for the progress report (DP-8) and the end-of-term report (DP-12 alternate), since these were evaluated on the quality of the technical work, as well as the communication (including graphs, drawings, writing, following the correct format, and completeness). Several teams required counseling or asked for a meeting to review their reports. The instructor was also the sponsor of four teams, which commanded a larger time commitment than was anticipated.

To pass the course, students had to earn a score of $72 \%$ or greater both for the individual and the team components. No grade of D was given; students either earned an A, B, C, or an F. This was to impress on the students that substandard work is not acceptable in professional engineers. The Design Committee is presently considering how to deal with two failing students. 


\section{Course Logistics 4-Required Materials and Available Resources}

A customized edition of the textbook was produced by McGraw-Hill ${ }^{12}$ by adding select chapters on ethics and design for $\mathrm{X}$ from the engineering design book by George E. Dieter ${ }^{13}$ to an earlier creative problem solving in engineering text ${ }^{5}$.

In addition to the textbook, the students had videotapes of the different lecture topics available to meet the needs of teams that had to miss a lecture while on a plant trip. Most lectures were in PowerPoint, with all slides available as handouts or on the course's website. Also all handouts with class logistics and information not in the textbook were posted on the website. An HBDI consultant was available to help with team formation, give a lecture, and answer questions.

The team advisors facilitated the student team's interaction with the sponsor and supervised their written report and technical progress; however, they were not usually experts in the project area but could refer the students to relevant sources of information on or off-campus. Student teams were given a lab and meeting space for their project, and technicians were available to help with fabrication of prototypes if necessary.

\section{Results}

The following are results noted by the end of the first semester:

- No teams were found to be dysfunctional, in contrast to the experience of past years. This achievement was noticed in particular by staff members in the Mechanical Engineering Department who had frequent interactions with previous design teams. All teams had at least one student each with strong analytical, organizational, or conceptual thinking preferences, and the teams knew they needed to pay attention to interpersonal factors and communication in their projects.

- Ground rules were found to be very valuable and helped the teams off to a good start, as well as handle or avoid conflict. The greatest difficulties were: leaders who charged off by themselves instead of getting the team involved, and team members who did not do the assigned work, missed team meetings, or showed no initiative.

- Most teams were well into the norming stage in team development by the end of the first term. Some had to backtrack when a new student joined the team-in essence repeat the forming and storming stages. Some learned to value the foreign students despite serious communication problems - they realized the likelihood of having to work with colleagues from other countries in their future employment and felt their current experience was giving them an advantage. Additional tips for reviewing their team development were given at the beginning of the second term. It is expected that all teams will be able to achieve a satisfactory performing stage by midterm of the second semester. To monitor this, they will be asked to submit another evaluation of their team's development. At this stage, team achievement should become foremost, without individual members shirking their responsibilities or wanting to be "stars."

- Once students realized the quality expectations for their reports, there was a marked improvement in written and oral communication.

- All project sponsors were satisfied with their team's progress and the level of communication they received. The design project proposal (DP-6A) was a key document for preventing misdirected projects. 
In their end of Semester 1 Report, one team expressed the value of the new approach best:

"We would have charged ahead with our first idea,

but then we were "forced" to use the creative problem solving process.

We now see that our final design solution is far superior to what we would have accomplished with our initial concept and limited range of thinking modes."

The mid-term progress report summary for the second semester (DP-8 alt.) is planned to be a 3page concise report of the progress of their report, together with a one-page evaluation of how they used the creative problem solving process and the insights gained from the HBDI. In particular, the instructor will seek to assess how team members with strong quadrant $\mathrm{C}$ and quadrant $\mathrm{D}$ preferences fared on their teams. Typically, in very quadrant A-dominant engineering teams, individuals with strong quadrant $\mathrm{C}$ and $\mathrm{D}$ thinking preferences may be treated as outsiders who do not receive much respect and consideration for their ideas.

One of the most exciting results of this capstone design course was with a company who had 15 of their employees take the HBDI (including product and process engineers, as well as marketing/sales people). As a whole, this group was evenly balanced between quadrant $\mathrm{A}$ and quadrant D thinking, an excellent combination for leading the organizational innovation effort. The process consisted of developing a core team of five people to work with their capstone design student team. Their task was to narrow down to two "best" concepts the ten ideas with the highest potential the team had worked out by the end of the first term. These will then be developed into new product lines. The company team will also work at instituting in their company the new innovation process initiated by the students. The other 10 people are available to rotate into this development team as their other work assignments allow. The company is now sponsoring a second team for the capstone class that started in the spring of 2007.

\section{Recommendations}

The recommendations address three different areas: (1) orientation meeting for the juniors who sign up for the capstone design class; (2) the logistics of preparing and teaching this integrated capstone design course, and (3) college-wide changes that could enhance the competence of the students for the design course.

Course Orientation: Ideally, engineering students signed up for the capstone design course should have a two-hour meeting before they leave campus at the end of the spring term of their junior year. They will need to be given the following information about what to expect and how to prepare for the course during the summer:

- This will be a "different" course-a true bridge between your previous highly structured, analytical engineering classes and the team-based work environment. You will be expected to be able to think conceptually and make good decisions; you will need to know how to communicate well and have good writing skills. There will be extensive reading assignments. Homework will not have "just one right answer"-you will learn how to find the "best" answer among several good choices. The course will require maturity, as well as creativity and good teamwork. You will not get a passing grade without producing quality work. 
- Check your e-mail frequently during the summer, as you will receive information on how to access the HBDI form. The results will be used for forming balanced project teams. You will also receive information on the available projects, and you can submit your top five choices. The staff will try their best to keep these choices in mind when forming the teams, but team assignment will also take into consideration the student's special qualifications, sponsor requests-forming balanced teams based on the HBDI profile results will be a priority. Your chances of getting on a preferred project are higher if you put some less "glamorous" projects on your list.

- Here are tips on the writing skills you are expected to have. Here are two or three samples of technical reports from engineering journals. Look at them closely-not to understand the technical content, but to learn from the format and writing style. Note how figures and tables are placed and captioned. Also review a basic book on writing and what common mistakes to avoid in grammar and spelling.

- In addition to enhancing your technical writing skills, we strongly recommend that you brush up on your word processing skills (including the use of style formats, as well as grammar and spell check). If you have the opportunity to take a workshop or seminar in word processing or technical writing this summer, take it, as it will give you a definite advantage. Throughout their careers, engineers spend 20 to 25 percent of their time writing, so learn to do it well. Also, there is a direct correlation between the size of vocabulary and promotion-so it is not too soon to start working on that angle as well.

Course Logistics: The following items are recommended to streamline the preparation and teaching of this course:

- Teams should be formed several weeks ahead of the start of class, to have time to make adjustments and switches. Students who want to switch need to submit their request in writing and give good reasons. They will not be allowed to join a team in a project area where they have previous experience if this was with a company where they had signed (or will be required to sign) a non-compete agreement.

- Advisors (and the design committee) need to attend an orientation meeting, so they can all be informed as to the objectives and process of the course and what their responsibilities will entail.

- The classroom assigned for this class needs to be ideally available 30 minutes prior and 30 minutes past the scheduled class hour. It was found that it was not possible to have a full class vacate a large auditorium and the capstone design students seated and ready for instruction when only 10 minutes were allotted. At times, the previous instructor did not even vacate the podium until just minutes before the start of class. This did not leave sufficient time to set up for PowerPoint presentations, equip a guest lecturer with a mike (and test it), and distribute or collect the class materials.

- To encourage students to not skip lectures, the brief 2-questions quiz will be used more frequently during the second semester, as a means to track attendance as well as the basic understanding of the concepts taught.

University-Wide Systemic Changes: Two changes are highly recommended that will enable the capstone design students to fully concentrate on their projects, have additional creative activities, and receive teaching on more advanced design techniques and quality tools for broader as well as more in-depth learning. 
- Provide a solid introduction to creative problem solving with team development during the first two years. This will also benefit learning in other classes, especially if these skills can be reinforced by other faculty. Most students would have liked to have had this advantage.

- To address the problem of having so many seniors who are woefully unprepared for producing an acceptable technical report will require the involvement and cooperation of many departments. For example, many students did not know how to caption tables or figures, not how to place these properly in the narrative text. The students would like to have a required technical writing course prior to their senior year-but it should not be boring. However, the writing problems are more basic: some were incapable of writing coherent, grammatically correct sentences. Also, they made appalling spelling errors, not knowing the difference between principle and principal, their and there, break and brake, or then and than. These deficiencies need to be addressed during the first year.

\section{Acknowledgments}

Four project teams received partial funding from NSF and NCIIA to develop marketable products. Twenty-two teams in the capstone design class described in this paper reviewed a draft of this ASEE paper and made numerous suggestions for improvement. Monika Lumsdaine was the HBDI practitioner who processed the capstone students' HBDI results; she also prepared the graphs and edited this paper. All these contributions are gratefully acknowledged.

\section{Bibliography}

1. Edward Lumsdaine, J. William Shelnutt, and Monika Lumsdaine, "Integrating Creative Problem Solving and Engineering Design," Session 2225, ASEE Conference, 1999.

2. Edward Lumsdaine, Harold A. Evensen, Paula F. Zenner, Monika Lumsdaine, "Educating Designers on Design via Distance Learning, Session 1625, ASEE Conference, 2005.

3. Ikujiro Nonaka and Hirotaka Takeuchi, The Knowledge-Creating Company: How Japanese Companies Create the Dynamics of Innovation, Oxford University Press, 1995.

4. Mark T. Mitchell, Michael Polanyi, ISI Books, 2006.

5. Edward Lumsdaine, Monika Lumsdaine, J.William Shelnutt, Creative Problem Solving and Engineering Design, McGraw-Hill College Custom Series, 1999.

6. $\quad$ www.hbdi.com $\rightarrow$ Resources $\rightarrow$ Video $\rightarrow$ Carte Blanche: Watch video! (South African News program on the HBDI and implementation at the University of Pretoria).

7. Monika Lumsdaine and Edward Lumsdaine, "Thinking Preferences of Engineering Students: Implications for Curriculum Restructuring," Journal of Engineering Education, April 1995, Vol. 84, No. 2, pp. 193-204.

8. Dorothy Leonard and Susaan Straus, "Putting Your Company's Whole Brain to Work," Harvard Business Review, July-August 1977, pp. 110-121.

9. Frank Coffield, David Moseley, Elaine Hall, Kathryn Ecclestone, Learning Styles and Pedagogy in Post-16 Learning: A Systematic and Critical Review, Learning and Skills Research Centre, www.LSRC.ac.uk, 182 pages, 2004.

10. Bruce Tuckman, "Developmental Sequence in Small Groups," Psychological Bulletin 63, pp. 384-399, 1965. A reprint is available at http://dennislearningcenter.osu.edu/references/GROUP\%20DEV\%20ARTICLE.doc.

11. Edward Lumsdaine, Martin Binks, Entrepreneurship from Creativity to Innovation, Trafford Publishing, 2007.

12. E. Lumsdaine, M. Lumsdaine, J.W. Shelnutt, George E. Dieter, Creative Problem Solving and Engineering Design 2, McGraw-Hill College Custom Series, 2005.

13. George E. Dieter, Engineering Design, McGraw-Hill, 2000. 


\section{APPENDIX}

If students keep up with their assigned reading and project timeline for the individual tasks and documents, preparing the design proposal (Document DP-6A) will be easy, since the information from the previous documents - commonly less than one page each-will only need to be reviewed by the adviser and then revised (if needed) and compiled into a nicely formatted report. For serious writing problems, students can be directed to the university's writing center for help.

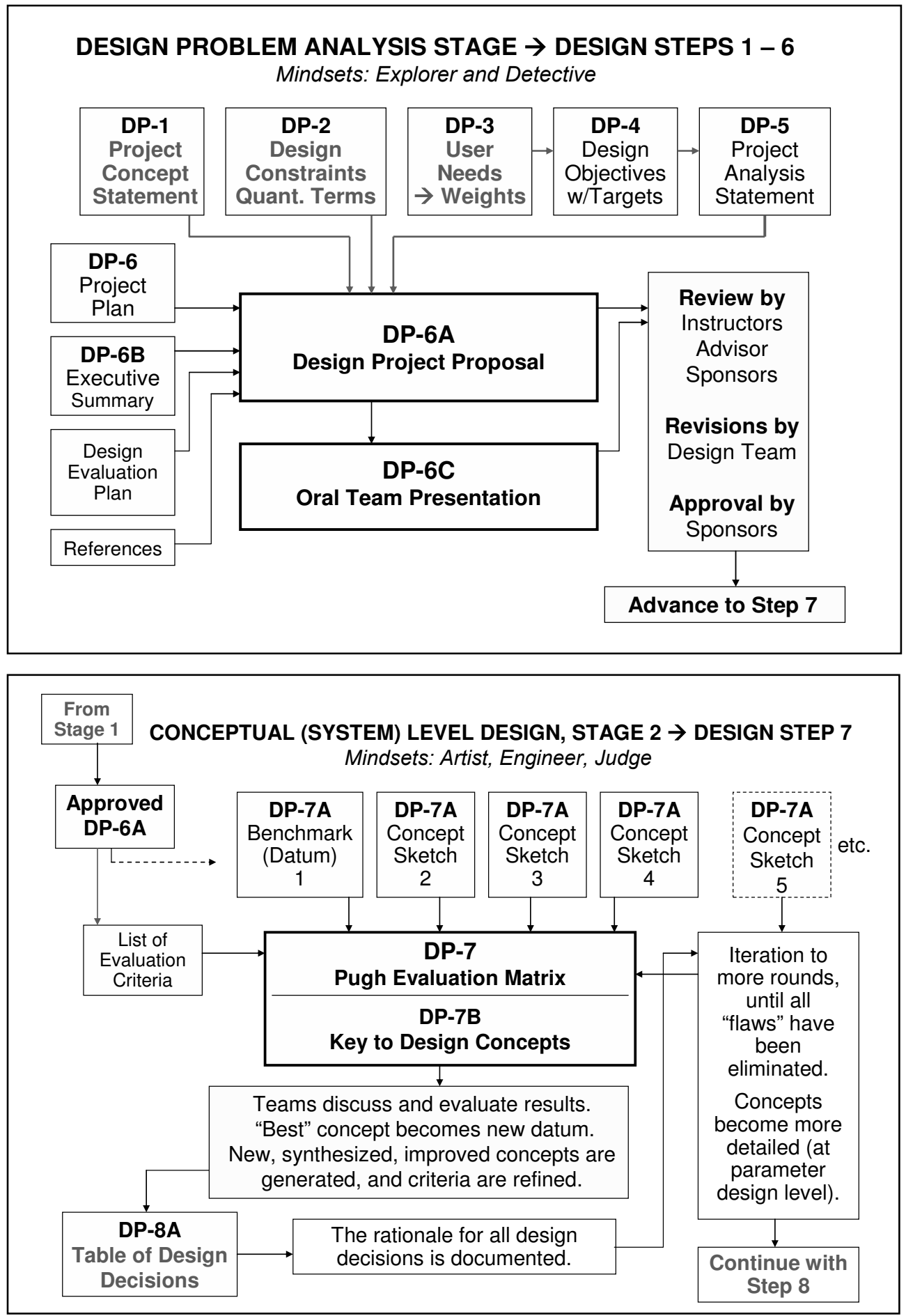

Figure A-1

Information flow

through the design analysis stage: Steps 1-6
Figure A-2

Information flow through the iterative conceptual design stage: Step 7.

The Table of Design Decisions (DP-8A) and the rationale for all decisions made is crucial but may be overlooked or just receive a cursory treatment by the students. 
Initially, students had trouble producing a quality progress report (DP-8), since they did not follow the required formats nor pay attention to quality writing. One of the most difficult documents to write and update was the Executive Summary-it needs to concisely describe the objectives of the project and what was accomplished to date. Many students just kept writing what they "hoped" to accomplish, not what they had actually done. Not all teams were able to include all the steps by the time this report was due, but they all reported on their progress to date (including an updated Gantt chart).
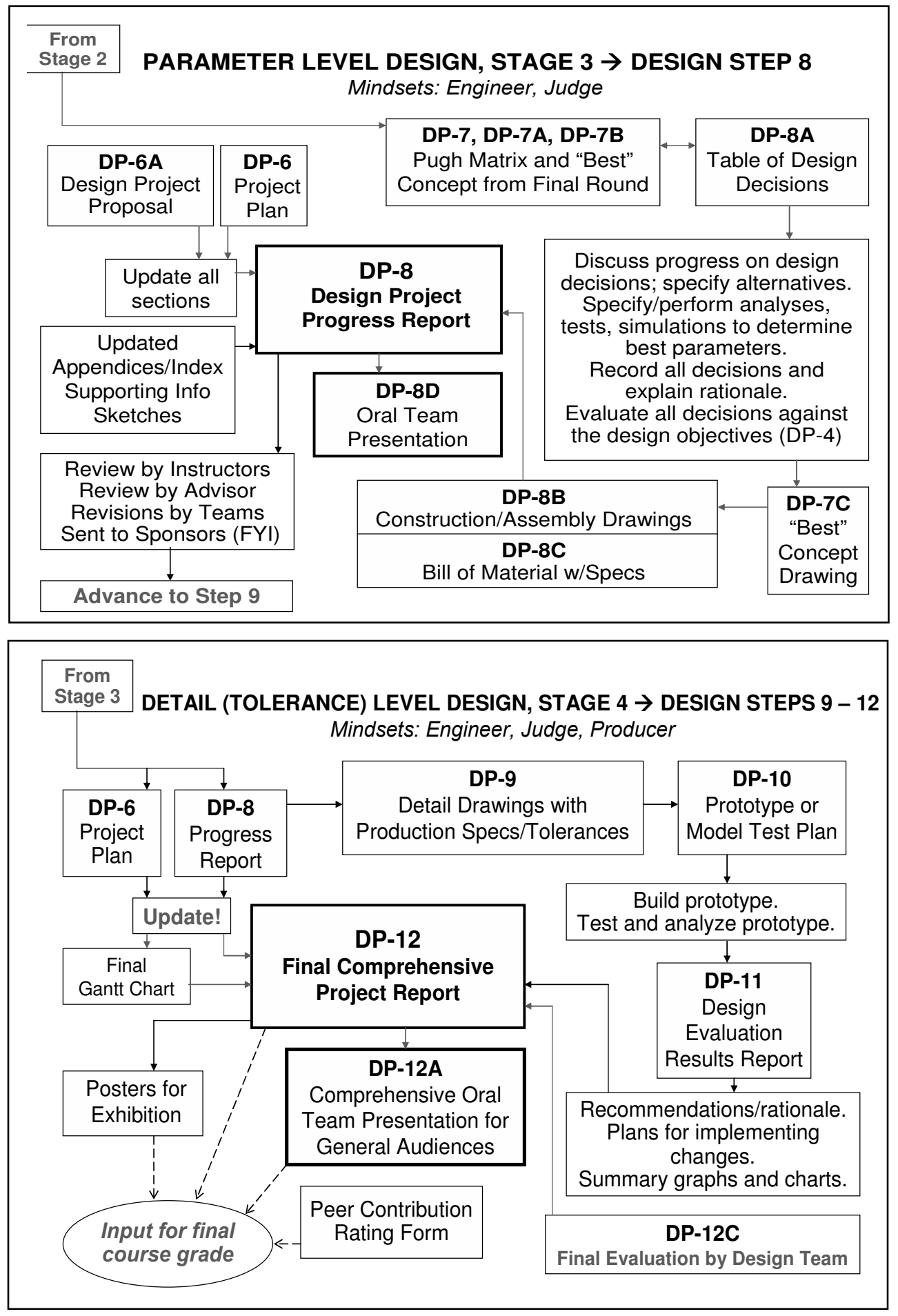

Figure $A-4$

Information flow through the detail level design stage: Steps 9-12.

For the end of the first term, amended instructions were provided for an "end of first term" report-in essence an updated, more comprehensive progress report. DP-12 will be required at the end of the second term. 